\title{
ANTECEDENTS OF WORD-OF-MOUTH: AN EXAMINATION OF CONSUMER- AND SECTOR-LEVEL EFFECTS
}

\author{
Alke Töllner, Technische Universität Dortmund, Germany \\ David M. Woisetschläger, Technische Universität Braunschweig, Germany
}

\begin{abstract}
Existing research considers word-of-mouth (WOM) as one of the oldest and most influential channels of communication in the marketplace (Ennew et al. 2000) and various examples provide evidence for this assumption. While positive WOM is regarded as a key factor to success (Katz and Lazarsfeld 1955, Murray 1991), negative WOM might substantially harm companies' success (Weinberger et al. 1981, Mizerski 1982). Therefore, the huge impact of (positive and negative) WOM on companies' success raises their interest on antecedents of WOM and encourages researchers to investigate the antecedents of WOM.
\end{abstract}

Although various studies suggest that the relevance of WOM and in conjunction with that its antecedents depend on product category attributes or sector factors (e.g., Richins and Roth-Shaffer 1988, Samson 2006), little is known if WOM communication really differs across contexts (service vs. product). These differences and knowledge about potential explanatory variables are important, as firms increasingly tend to publish their WOM or net-promoter-scores (NPS) in annual reports or use these scores as quality signal in advertising. The meta-analysis by de Matos and Rossi (2008) suggests a moderating impact of the industry sector (product vs. service) on the relationship between satisfaction and WOM, but do not find empirical support in their data. Using data of 1,147 respondents with each respondent evaluating one of 32 product categories, the aim of our study is to explore differences of WOM communication across a broad range of product categories as well as to explain these differences using specific category characteristics. In doing so, we do not explicitly distinguish between products and services. Instead, we characterize each category using the following five variables: level of prestige, interaction intensity, perceived purchase risk, level of experience attributes, and level of credence attributes. As many researchers point out that WOM communication might depend on various category characteristics (e.g., Bayus 1985, Bone 1992, Hartline and Jones 1996, East et al. 2001, Hennig-Thurau et al. 2004, Brown et al. 2005, Walsh and Beatty 2007), this study aims at closing this research gap.

Data for our study comes from two different sources: survey-based data from a representative field study, and expert ratings from several industry experts that are used as assessment of category characteristics. First, we collected data via a representative online survey among members of an online panel provider. A total of 1,147 respondents participated in the survey. Second, we conducted expert interviews with a set of 12 experts, such as academics in the field of business research, consultants, and respondents in other functions (e.g., officials from the chamber of commerce). The experts were asked to evaluate each of the 32 product categories according to several characteristics. The categories were chosen to represent the most important and relevant consumer markets such as automobiles, fashion, furniture, hotels, jewelleries, retailers, sport articles, telecommunication services, etc. (full list available upon request).

Due to the dyadic nature of the data, this study uses a multilevel structural equation modelling approach to test the relationships of the two-level data in a single analysis, accounting for the variability associated with each level of the hierarchy. Although the assessment of individual-level determinants of WOM intention was not in the focus of this paper, a conclusion of the empirical analysis is that customer satisfaction dominates other, more personality-describing factors. On the category-level, results reveal that level-differences in WOM depend on the amount of prestige associated with a category. Additionally, WOM is higher with higher levels of experience- and credence attributes. Contrary to our conceptual model, the levels of risk and the level of interaction intensity within the product categories are unrelated to level-differences of WOM. Potentially, risk is already covered implicitly in the share of experience and credence attributes. Concerning the insignificant effect of interaction intensity, a potential explanation could be that individuals associate each product category more heterogeneously in terms of interaction intensity (as multiple sales channels ranging from highly personalized and interactive channels to technology-mediated channels without human interactions exist) relative to the assessments of the expert panel. The findings may help marketing managers to learn why scores differ across categories, and could provide a basis for calculation of adjustment factors to provide cross-sector equivalent key performance indicators such as WOM. Differences across sectors matter, because sectors might seem as more service-oriented if they receive higher scores for WOM (or NPS, as used by many firms), even if their score-advantage is a result of category characteristics.

References available upon request. 